Instead of focusing on the differences between the age samples, represented by the spread between the functions in Fig. 1, we prefer to emphasize the basic similarity in all of the age samples. Namely, because all groups encode categorically in STM, they all show the effects of PI in appropriate circumstances. Qualitatively similar behavior by preschool and school-age children in STM is especially impressive, since striking changes have been observed to occur in young children's cognitive, social, and linguistic behaviors at about age 6 , corresponding to an important stage boundary in Piaget's developmental theory (Piaget, 1950) and to the hypothesized onset of verbal mediation by learning theorists (Kendler \& Kendler, 1962).

This is not to suggest that developmental differences in STM do not occur. Categorical encoding requires that Ss respond to a group of stimuli as members of the same class. A previous study of school-age children's performance in tasks using these procedures (Wagner, 1970) reported that taxonomic classes (animals and colors) were the only classes for which the youngest Ss tested (CA 9) showed evidence of any PI or its release. Phonemic classes (words that rhyme) showed PI but no release, while sense impression classes (round things and white things) showed no PI and, of course, no release. Differential susceptibility to PI as a function of stimulus category suggests that these procedures can be used to assess concept formation in young children. A special advantage of the procedure is that the individual does not have to be able to name the class to which the stimuli belong or even to be consciously aware that they come from a particular category (Wickens, 1970).

An invariant memory function that manifests performance differences as a function of the extent to which the stimulus classes are psychologically relevant also lends support to Piaget's theory, which interprets limitations in chiidren's memory as a result of incompletely developed schemes for dealing with classes and relations rather than restricted ranges of experience or shorter conditioning histories.

\section{REFERENCES}

Battig, W. F., \& Montague, W. E. Category norms for verbal items in 56 categories: A replication and extension of the Connecticut category norms. Journal of Experimental Psychology Monograph, 1969, 80, Part 2, 46 pp.

Cann, L. F., Liberty, C., Shafto, M., \& Ornstein, P. A. Release from proactive interference with young children. Developmental Psychology, 1973, 8, 396.

Kendler, H. H., \& Kendler, T. W. Vertical and horizontal processes in problem-solving. Psychological Review, 1962, 69, 1-16.

Piaget, J. The psychology of intelligence. New York: Harcourt. Brace \& World, 1950.

Wagner, J. F. A developmental study of categorical organization in short-term memory. Unpublished doctoral dissertation, The University of Connecticut, 1970.

Wickens, D. D. Encoding categories of words: An empirical approach to meaning. Psychological Review, 1970, 77, 1-15.

Wickens, D. D., Born, D. G., \& Allen, C. K. Proactive inhibition and item similarity in short term memory. Journal of Verbal Learning \& Verbal Behavior, 1963, 2, 440-445.

(Received for publication October 5, 1973.)

\title{
Effects of grouping and crowding on learning in isolation-reared adult rats*
}

\section{WILLIAM E. WOOD and WILLIAM T. GREENOUGH University of Illinois, Champaign, Ill. 61820}

Rats reared in isolated and overcrowded environments are inferior to those from small groups in complex learning tasks. To examine the age dependence of this phenomenon, adult rats isolated from weaning were placed in groups of 1,4 , and 16 for either 1 or 4 weeks. One week of grouping enhanced Lashley III maze

\footnotetext{
* Research performed while first author was a predoctoral trainee in biopsychology supported by US PHS 5 T01 MH 10715; research also supported by National Institute of Human Development Grant HD 06862, PHS Grant FR07030, and the University of Illinois Research Board. Address for reprints: William T. Greenough, Department of Psychology, University of Illinois, Champaign, Ill. 61820 .
}

performance, while 4 weeks' grouping did not. One week of grouping did not affect shock avoidance brightness discrimination, but after 4 weeks, the group of 16 was superior. Hence, grouping or crowding in adulthood tends to reverse learning deficits produced by isolation rearing.

The role of the developmental and adult social environment in behavioral performance has received considerable attention, although it is often ignored in experiments in which other variables are examined. Much research has focused upon the extremes of social density: isolation and crowding. Both extremes appear to be stressful, at least in rodents, in terms of adrenal 
Table 1

Effects of Grouping on Behavior and Weights (Mean $=$ SEM)

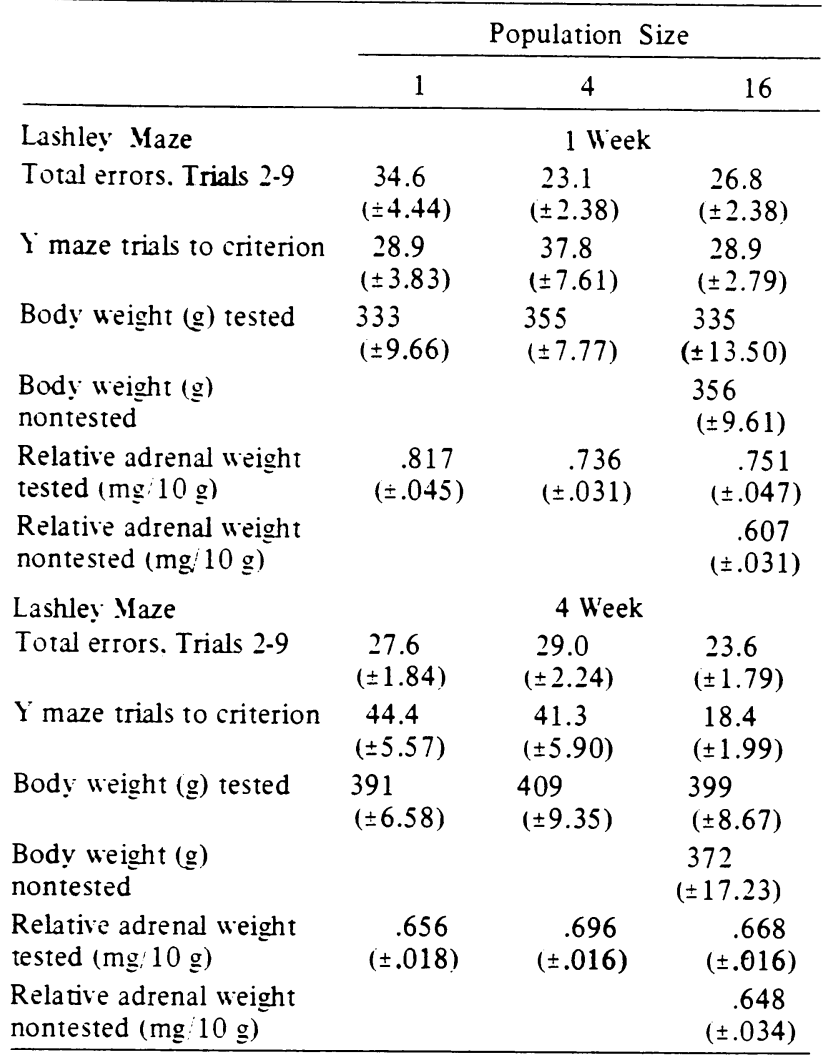

lote-1 $=16$ in each group.

weight (Baer. 1971: Brain \& Nowell, 1970), pituitary weight (Bell. Miller, Ordy, \& Rolsten, 1971: Quay, Bennett. Rosenzweig, \& Krech, 1969), and various abnormal behavior patterns (e.g., Baer, 1971; Bell et al. 1971: Calhoun. 1962; Scott \& Fredericson. 1951). In adult animals, the stressful effects of isolation seem to increase to some degree as it is prolonged (Baer. 1971; Lovely. Pagano, \& Paolino, 1972), while in developing rodents. isolation immediately following weaning may have a profound effect (Ader, 1965: Geller. 1971). Whether the effects of crowding are more pronounced with duration or during development is not clear, although reproductive maturation may be slowed by increased social contacts (Christian \& Davis, 1964).

Recently, Goeckner, Greenough, \& Mead (1973) reported that rats reared in overcrowded environments showed impaired acquisition of complex appetitively and aversively motivated learning tasks. In a later study (Goeckner. Greenough. \& Maier, 1974), overcrowded rearing produced a greater deficit in avoidance acquisition than did isolated rearing. Since the animals were kept in their experimental environments during testing. it was not clear whether the debilitating effects of the overcrowded environment were due to its impact during rearing or to the short-term proactive or concurrent effects of the continuing crowding stress during behavioral training. Recent reports have indicated that the immediate effects of a grouping upon adrenal reactivity and resistance to stress can be quite pronounced (Plaut \& Grota. 1971: Plaut. Ader. Friedman. \& Ritterson, 1969).

The present study was designed to determine the effects of short-term and long-term adult grouping and overcrowding on acquisition of complex learning tasks in previously isolated rats. It was thought that 1 week of crowding prior to training would indicate the effects of an overcrowded environment during behavioral testing per se. while 4 weeks of crowding prior to testing would show the effects of longer-term overcrowding stress in adulthood on acquisition measures. Group sizes of 1,4. and 16 rats were chosen on the basis of the Goeckner et al (1973) and Goeckner et al (1974) data.

\section{METHOD}

\section{Subjects and Housing Procedure}

Male Sprague-Dawley albino rats (descendents of ARS Sprague-Dawley, Madison, Wis., stock), born in the laboratory, were separated from their litters and individually housed in sawdust-floored translucent plastic tubs at 35 days of age. At 95 days of age, they were rehoused in experimental cages. Individually housed (GPI) rats were kept in $22.5 \times 30 \times 25 \mathrm{~cm}$ (high) sheet metal cages with wire mesh bottoms and fronts. Socially housed animals were placed in groups of 4 (GP4) or 16 (GP16) in $90 \times 30 \times 25 \mathrm{~cm}$ (high) wire mesh cages. Food and water were available ad lib except as appropriate during behavioral testing, and animals were maintained on a 12-h diurnal light cycle. Animals were handled once weekly for weighing and, except for maintenance, were not otherwise disturbed. After either 1 or 4 weeks of such housing, behavioral testing was begun. Each size-duration group contained 16 animals: thus, a total of 96 animals underwent behavioral testing, while an additional 32 nontested animals were included in the adrenal weight data.

\section{Behavioral Testing}

Ss were kept in the experimental environments during behavioral testing. All animals from the isolated and GP4 environments were tested, while eight animals were randomly selected from each GP1 6 for testing. Three days prior to beginning. all Ss were placed on a $233 / 4$-h water deprivation schedule. Ss were trained in 13 trials over 7 days to run a $110-\mathrm{cm}$ gray straight alley for $0.1 \mathrm{ml}$ of water reward. During testing hours, Ss occupied individual stainless steel cages, and the extra members of GP16 were given water. Each $\mathrm{S}$ received $15 \mathrm{~min}$ access to water prior to returning to his home cage. Following pretraining. Ss were given three trials per day for 3 days on a four-unit 8-cul Lashley III alley maze (details: Greenough \& McGaugh, 1965). Groups were balanced for time of day tested. Following the final maze trial. Ss were returned to ad lib water and rehabilitated for 2 days. Over the next 2 days, they were trained, in a balanced order, to avoid or escape footshock $(0.6 \mathrm{~mA})$ by running to the lighted arm of a symmetrical Y-maze (details: Goeckner et al. 1973). Ss were trained according to a Gellerman series (Gellerman, 1933) to a criterion of 9 out of 10 correct initial choices (escape or avoid). On the following day, all animals received a lethal dose of sodium pentobarbital, and both adrenal glands were removed. cleaned of surrounding adipose tissue. and weighed.

\section{RESULTS}

Results for all measures are presented in Table 1. In contrast to the data for overcrowded rearing. the effects of both grouping and overcrowding of isolation-reared adults seemed to be (generally) positive. with the larger 
group showing the greater effect. For the Lashley III maze, 1 week of differential housing produced an overall effect $(F=3.97, p<.05)$ in which both GP4 and GP16 were superior to the isolates $(p<.05$ and $p<.10$, respectively, by post hoc comparisons; Winer, 1962). The effects after 4 weeks fell short of significance $(F=$ $2.25, \mathrm{p}>.10)$. In the $\mathrm{Y}$-maze, no significant differences $(\mathrm{F}=1.15, \mathrm{p}>.25)$ occurred in trials to criterion after 1 week, perhaps reflecting the interaction between adaptation to the novel housing and this more stressful task. After 4 weeks, a significant effect of housing appeared $(F=8.49, p<.01)$, with GP16 superior to both GP4 $(F=11.06, p<.01)$ and GP1 $(F=14.21$, $\mathrm{p}<.01)$

Since adrenal weight was measured for both the 16 animals from GP16 which were behaviorally tested at each time point, and from the 16 which were not, it was possible to assess the effects of behavioral testing on this measure. Among animals grouped for 1 week prior to testing, the tested animals showed a $20 \%$ higher relative (to body weight; Brain \& Nowell, 1969) adrenal weight $(F=5.67, p<.05)$. After 4 weeks' housing, the behavioral testing increment was only $3 \%(\mathrm{~F}=.192, \mathrm{p}=$ n.s.). It appeared that behavioral testing interacted with the lack of time for adjustment to new housing, since the (behaviorally tested) 1 -week groups all exceeded the 4-week groups in relative adrenal weight $(F=12.43$, $\mathrm{p}<.01$ ), while the untested (GP16) animals did not differ significantly at the two time points $(F=.608, p=$ n.s.).

\section{DISCUSSION}

In contrast to previous work on overcrowded rearing (Goeckner et al, 1973; Goeckner et al, 1974), these data indicate that grouping or crowding of previously isolated adult rats tends to facilitate acquisition of complex tasks. This clearly indicates that the debilitating effects of overcrowding result from rearing in the overcrowded environment rather than from the effects of crowding prior to or during behavioral testing. Goeckner et al (1973) found that animals reared from weaning in a group of 16 in cages identical to those of the present study were retarded, in comparison to animals in cages of 4 , on the Y-maze task; in the present study, animals in cages of 16 were generally superior to those in cages of 4 on the Y-maze. In the Lashley III maze, the tendency toward facilitation in GP16 (after 4 weeks) also opposes the tendency towards worse performance in the Goeckner et al (1973) study.

Just why overcrowding facilitated performance is less clear. It seems likely that the effect resulted because the animals had been isolated from late development to the onset of the experimental environments. Presumably, the animals had developed the symptoms of chronic isolation stress described in the introduction. While these symptoms may facilitate certain simple tasks (e.g., Lovely, Pagano, \& Paolino, 1972), isolated animals tend to be inferior to those socially housed (uncrowded) on more complex tasks (Greenough, Wood, \& Madden, 1972: Goeckner et al, 1974). Several reports have indicated that various aspects of isolation are reversed when the animals are regrouped (Christian, 1955; Hatch, Wiberg, \& Zawidzka, 1965: Plaut \& Grota, 1971). Christian reported that the adrenal effects of crowding following isolation were greater, in a 3-week period, with increasing group size up to 16 animals. This suggests that those aspects of isolation which contribute to poor performance on complex learning tasks may be reversed (in a 4-week period) to a greater extent by overcrowding than by less intense social grouping.

In general, taken with previous findings, these results indicate that overcrowding during development affects the ability of rats to perform complex tasks, and that these results cannot be attributed to the proactive or concurrent effects of crowding during testing. Whether crowding for longer periods following maturation may have similar effects-or whether negative effects may be produced only during development-remains to be determined.

\section{REFERENCES}

Ader, R. Effects of early experience and differential housing on behavior and susceptibility to gastric erosions in the rat. Journal of Comparative \& Physiological Psychology, 1965, 60, 233-238.

Baer, $H$. Long-term isolation stress and its effects on drug response in rodents. Laboratory Animal Science, 1971, 21, 341-349.

Bell, R. W., Miller, C. E., Ordy, J. M., \& Rolsten, C. Effects of population density and living space upon neuroanatomy, neurochemistry, and behavior in the C57B $1 / 10$ molise. Journal of Comparative \& Physiological Psychology, 1971, 75, 258-263.

Brain, P. F., \& Nowell, N. W. Some endocrine and behavioral changes in the development of the albino laboratory mouse. Communications in Behavioral Biology, 1969, 4, 203-220.

Brain, P. F., \& Nowell, N. W. The effects of differential grouping on endocrine function of mature male albino mice. Physiology \& Behavior, 1970,5,907-910.

Calhoun, J. B. Population density and social pathology. Scientific American, 1962, 206, 139-148.

Christian, J. J. The effect of population size on the weights of the reproductive organs of white mice. American Journal of Physiology, 1955, 13, 81-88.

Christian, J. J., \& Davis, D. E. Endocrines, behavior, and population. Science, $1964,146,1550-1560$.

Geller, E. Some observations on the effects of environmental complexity and isolation on biochemical ontogeny. In M. B. Sterman, D. J. McGinty, and A. M. Adinolfi (Eds.), Brain development and behavior. New York: Academic Press, 1971.

Gellerman, L. W. Chance orders of alternating stimuli in visual discrimination experiments. Journal of Genetic Psychology, $1933,42,206-208$.

Goeckner, D. J., Greenougn, W. T., \& Maier, S. F. Escape learning deficit after overcrowded rearing in rats: Test of helplessness hy pothesis. Bulletin of the Psychonomic Society, $1974,3,54-56$.

Goeckner, D. J., Greenough. W. T., \& Mead, W. R. Deficits in learning tasks following chronic overcrowding in rats. Journal of Personality \& Social Psychology, 1973, 28, 256-261.

Greenough, W. T., \& McGaugh, J. L. The effect of strychnine sulphate on learning as a function of time of administration. Psychopharmacologia, 1965, 8, 290-294.

Greenough, W. T., Wood, W. E., \& Madden, T. C. Possible memory storage differences among mice reared in environments varying in complexity. Behavioral Biology, environments vary

Hatch, A. M., Wiberg, G. S., \& Zawidzka, Z. Isolation sy ndrome in the rat. Toxicology \& Applied Pharmacology, 1965, 7. 737-745.

Lovely, R. H., Pagano, R. R., \& Paolino, R. M Shuttle-box-avoidance performance and basal corticosterone levels as a function of duration of individual housing in rats. Journal of Comparative \& Physiological Psychology, 1972, 81, 331-335.

Plaut, S. M., Ader, R., Friedman, S. B., \& Ritterson, A. L. Social factors and resistance to malaria in the mouse: Effects of group vs individual housing on resistance to Plasmodium berghei infection. Psychosomatic Medicine, 1969, 31 5 36-552.

Plaut, S.'M., \& Grota, L. J. Effects of differential housing on adrenocortical reactivity. Neuroendocrinology, 1971, 7 , 348-360.

Quay, W. B., Bennett, E. L., Rosenzweig, M. R., \& Krech, D. Effects of isolation and environmental complexity on brain and pineal organ. Physiology \& Behavior, 1969, 4, 489-494.

Scott, J. P., \& Fredericson, E. The causes of fighting in mice and rats. Physiological Zoology, 1951, 24, 273-309.

Winer, B. J. Statistical principles in experimental design. New York: McGraw-Hill, 1962.

(Received for publication October 16, 1973.) 